\title{
Detection of Human Papilloma Virus Type 16 in Epithelial Ovarian
}

\section{Tumors Samples}

\author{
Masoud Dadashi, ${ }^{1,2}$ Gita Eslami, ${ }^{2,}$ Ebrahim Faghihloo, ${ }^{2}$ Ali Pourmohammad, ${ }^{2}$ Jalil Hosseini, ${ }^{1}$ Robabeh \\ Taheripanah, ${ }^{1}$ and Zahra Arab-Mazar ${ }^{3}$ \\ ${ }^{1}$ Infertility and Reproductive Health Research Center, Shahid Beheshti University of Medical Sciences, Tehran, Iran \\ ${ }^{2}$ Department of Microbiology, School of Medicine, Shahid Beheshti University of Medical Sciences, Tehran, Iran \\ ${ }^{3}$ Infectious Diseases and Tropical Medicine Research Center, Shahid Beheshti University of Medical Sciences, Tehran, Iran \\ "Corresponding author: Gita Eslami, Department of Microbiology, School of Medicine, Shahid Beheshti University of Medical Sciences, Tehran, Iran. Tel: +98-2123872556, Fax: \\ +98-2123876472, E-mail: g_eslami@yahoo.com
}

Received 2016 June 01; Revised 2016 December 18; Accepted 2016 December 18.

\begin{abstract}
Background: Ovarian carcinoma is the most common malignancy in women and is a cancer with a $15 \%$ - $50 \%$ prevalence in the world. Human papilloma virus (HPV) is considered a factor in cervical and ovarian cancer (OCa) and is related to squamous cell carcinoma in the cervical region. The effect of fixed infection may cause chronic inflammation, in the cancer of ovaries it has received very rare attention, although a background of pelvic inflammatory disease (PID) in a case-control study is associated with a higher risk for ovarian carcinoma. HPV-16 is one type of HPV and the most common and important cause of cervical carcinoma in the developed world.

Objectives: The aim of this investigation was to evaluate the incidence of HPV-16 in patients with OCa who referred to Imam Hossein hospital of Shahid Beheshti University of Medical Sciences, Tehran, Iran.

Methods: In this case-control study that was conducted since May 2015 to October 2015 in Tehran, 140 samples were studied which were obtained from patients with OCa. After obtaining the samples from OCa tissue by a pathologist, for DNA extraction, samples were transferred to the laboratory of the university. DNA was extracted with Kit (intron biotechnology Co. Korea) according to the manufacturer's instructions. To confirm the presence of HPV-16 in the samples of OCa, specific primers for the L1 gene of HPV were designed and standard PCR method was used for the detection of HPV. PCR product was sequenced to confirm the presence of HPV-16. Results: Out of 140 samples of OCa, 70 (50\%) samples were malignant cancer and 70 (50\%) were benign cancer as the control group. Out of 70 malignant samples 25 (36.0\%) were HPV-16 positive. 2.8\% of the tissue samples of the control group were positive for HPV-16. Conclusions: These results show a feasible role of HPV-16 in the carcinogenesis of OCa. According to these results, infection with HPV may play a relative role in the spread of OCa or it could comfort its development.
\end{abstract}

Keywords: HPV, Ovarian Cancer, Malignancy, PCR

\section{Background}

Human papillomavirus (HPV) are double stranded DNA and small viruses that are related to the papillomaviridae family. Papillomaviruses were first recognized in patients with cervical cancer and they are of the most important sexually transmitted viruses in the world $(1,2)$ and they are now understood to be needed but inexpressive for the rise of genital cancer (3-5). There are more than 100 known types of HPV of which at least 15 HPV types have been ranked as high pathogenic (HPV 16, 18, 35, 31, 39, 51, $45,56,52,66,59,69,68,82$, and 73 ), whiles those related to moderate warts of genitals and skin are low pathogenic types (HPV 6, 11, 43, 42, 40, 44, 61, 54, 72, 70, 81) for the cancer of the genital region in women $(6,7)$. Infection with carcinogenic HPV types is noted as the major reason for the increase of all invasive cancers of cervical region and the neoplasia of intraepithelial cervical carcinoma (8-10). OCa is the utmost usual abnormality of the females in the cervix $(11,12)$ and the most lethal of the gynecologic malignancies with $16 \%$ - 51\% globally. OCa ranked first with 41.2\% and the cancers of endometrium and cervix, respectively, ranked second and third among the gynecological cancers (13). In 2005, 24,498 cases of cancer in the female population were reported that in 1923 cases, the cancer was related to the ovary (Gynecological), so that 793 cases were about OCa that included $41.2 \%$ of all the gynecological cancers. In recent years, it has been reported that the rate of OCa from 192,000 in 2005 has increased to 20,000 in $2008(13,14)$. Therefore, the presence of HPV infection in the epithelial cell of the ovarian carcinoma has been a marvelous subject (15). Anal, oropharyngeal, penile, vulvar, and HPV-related tumors, represent a further $0.7 \%$ of the entire carcinoma regions in both genera (women and 
men), so that HPV is said to be accountable for $5.2 \%$ of the entire carcinoma worldwide $(6,16)$. In other microorganisms in the domain of bacteria such as Mycoplasma genitalium, Chlamydia trachomatis, and Neisseria gonorrhea are known worldwide as a risk factor for the cancer of the genital area $(17,18)$. We sought to study and analyze the presence of the HPV-16 in the paraffinized blocks of women with ovarian carcinomas who referred to Imam Hossein hospital of Shahid Beheshti University of Medical Sciences, Tehran, Iran.

\section{Methods}

\subsection{Samples Collection}

This case-control study was conducted since May 2015 to October 2015. In this pilot study, $70 \mathrm{OCa}$ (case group) and 70 non-OCa (control group) pathological specimens were collected by a pathologist from women aged between 22 to 60 years who referred to Imam Hossein hospital (governmental center), Tehran, Iran since 2004 to 2014. Demographic data including histological type of cancer, pathological stage of cancer, and ovarian intraepithelial neoplasia (OIN) were recorded. Then formalin-fixed and paraffinembedded tissue section of open ovariectomy, core needle biopsy, and trans urethral resection of the oval(TURO) samples were examined from patients with OCa and, also, from patients with benign OCa (BOCa). A single pathologist experienced in OCa pathology carried out the microscopic assessment of the microscopic samples to determine the cancerous and non-cancerous tissue differentiation. The best paraffin-embedded block containing cancerous tissue of the patients with OCa was selected for the examination. Samples were transported to the department of microbiology, school of medical sciences, Shahid Beheshti University of Medical Sciences for further analysis.

\subsection{DNA Extraction}

DNA was extracted from paraffin-embedded tissue and blocks which were formalin-fixed by G-spin TM total DNA extraction Kit (iNtRON Biotechnology Co. Korea). First, the paraffin blocks were sliced into thin pieces using a sterile razor bladder and were placed in a $1.5 \mathrm{~mL}$ tube (not more than $25 \mathrm{mg}$ ). According to the manufacturer's instruction, xylene was used to remove the paraffin and then the bacterial DNA was extracted from the tissue and the measure of their concentration was stored at $-20^{\circ} \mathrm{C}$.

\subsection{Standard $P C R$}

PCR assay for the detection of HPV was designed and used specific primers (L1-F5'-TTTGTTACTGTGGTAGATACTAC -3') and (L1-R 5'- GAAAAATAAACTGTAAATCATATTC -3') of HPV
PCR detection Kit (Pars Tous CO. Iran), respectively. Primers within the HPV PCR mix were specific for conserved L1 coding region in the HPV genome. Amplification protocol for the detection of HPV is shown in Table 1. The PCR products were analyzed on $2 \%$ agarose gel electrophoresis and the gel was stained with ethidium bromide $(0.5 \mu \mathrm{g} / \mathrm{mL})$ and viewed by UV transilluminator. The presence of $150 \mathrm{bp}$ fragments was positive for HPV.

Table 1. Amplification Protocol for the Detection of HPV

\begin{tabular}{l|c|c}
\hline Cycle & Time & Temperature \\
\hline \multirow{1}{*}{$\mathbf{4}$} & 5 Minutes & 94 \\
\hline \multirow{2}{*}{$\mathbf{4 0}$} & 30 Seconds & 94 \\
\cline { 2 - 3 } & 45 Seconds & 60 \\
\cline { 2 - 3 } & 30 Seconds & 72 \\
\hline \multirow{1}{*}{} & 5 Minutes & 72 \\
\hline
\end{tabular}

\subsection{Sequencing}

In order to purify the PCR products, the PCR purification kit (Bioneer Co. Korea) was used and the sequencing of forward strand was done by the Bioneer company (Korea). The nucleotide sequences were analyzed with Chromas 1.45 and MEGA-4 software and BLAST in NCBI.

\subsection{Statistical Analysis}

Statistical package for social sciences (SPSS) software (version 21) was used for the demographic data analysis.

\section{Results}

In a total of 140 study patients, there were 70 samples of women with OC and 70 samples of women with BOCa as controls. HPV-16 was detected in 25 (36.0\%) samples out of 70 OC patients and there were $2(2.8 \%) \mathrm{HPV}-16$ positive samples in the control group (Figure 1).

\subsection{The Results of PCR}

Standard PCR assay for the detection of HPV-16 was used. Overall, 25 (36.0\%) of OCa samples were positive for the presence of HPV-16 and 2.8\% of BOCa samples (control group) were positive for HPV-16 presence. The results of this study showed that in the experimental group (OCa) and the control group (BOCa) there are positive cases of HPV-16. The sequences of L1 gene in HPV-16 isolated from the patients were the same (http://multalin.toulouse.inra.fr/multalin/cgibin/multalin.pl) (Figure 2). There was no significant relationship between the prevalence of HPV-16 and the patients' age. 


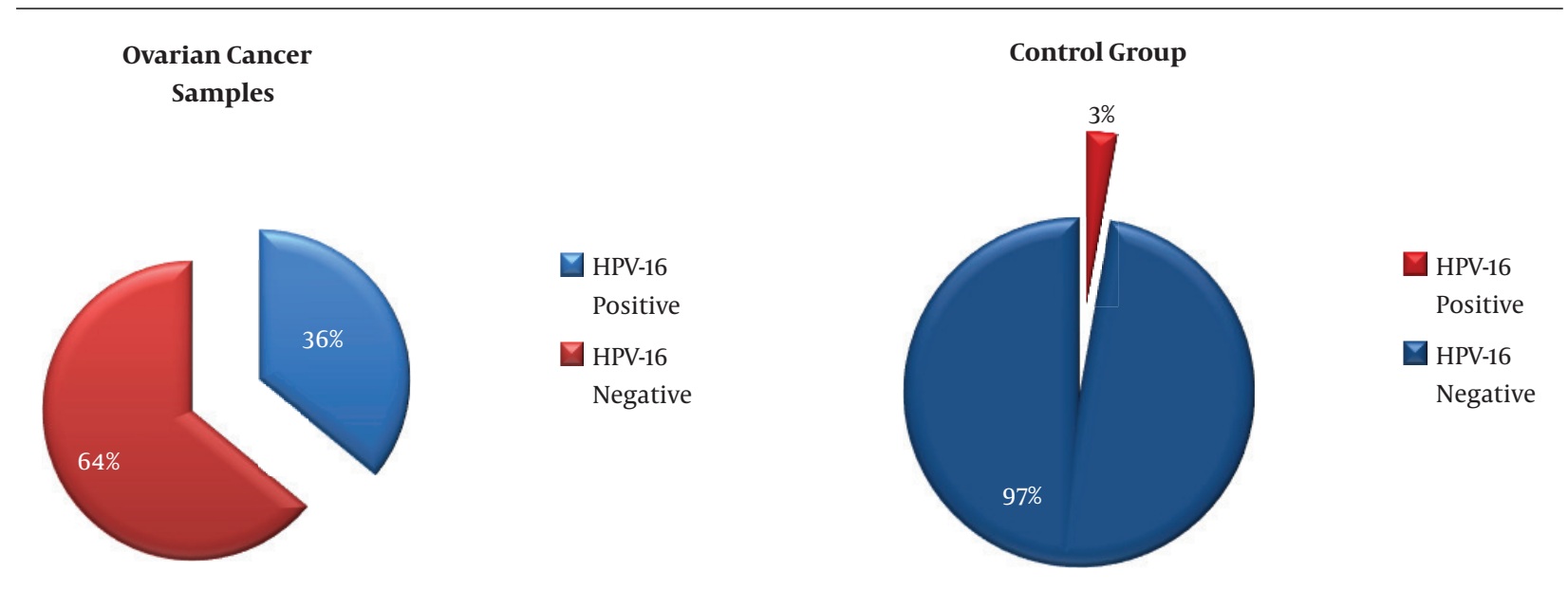

Figure 1. The Distribution of HPV-16 in Case and Control Groups of Study

\begin{tabular}{|c|c|c|c|c|c|c|c|c|c|c|c|c|c|c|}
\hline & 131 & 140 & 150 & 160 & 170 & 180 & 190 & 200 & 210 & 220 & 230 & 240 & 250 & 260 \\
\hline $\begin{array}{r}\text { HPV-16 } \\
\text { seq } \\
\text { Consensus }\end{array}$ & \multicolumn{14}{|c|}{ 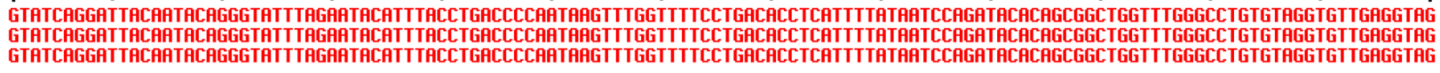 } \\
\hline & 261 & 270 & 280 & 290 & 300 & 310 & 320 & 330 & 340 & 350 & 360 & 370 & 380 & 390 \\
\hline $\begin{array}{r}\text { HPV-16 } \\
\text { seq } \\
\text { Consensus }\end{array}$ & \multicolumn{14}{|c|}{ 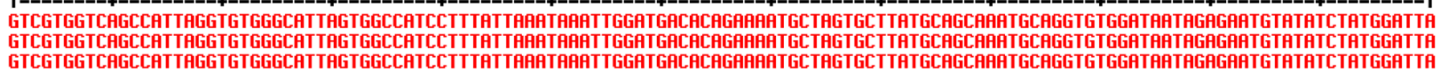 } \\
\hline & 391 & 400 & 410 & 420 & 430 & 440 & 450 & 460 & 470 & 480 & 490 & 500 & 510 & 520 \\
\hline $\begin{array}{r}\text { HPV-16 } \\
\text { seq } \\
\text { Consensus }\end{array}$ & \multicolumn{14}{|c|}{ 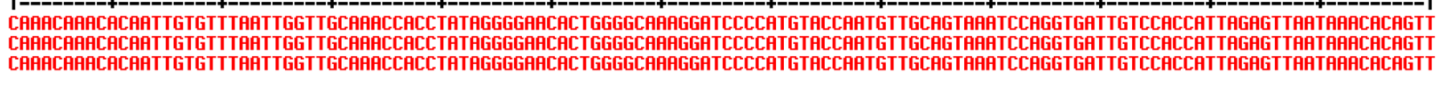 } \\
\hline & 521 & 530 & 540 & 550 & 560 & 560 & 580 & 590 & 600 & 610 & 620 & 630 & 640 & 650 \\
\hline $\begin{array}{r}\text { HPV-16 } \\
\text { seq } \\
\text { Consensus }\end{array}$ & \multicolumn{14}{|c|}{ 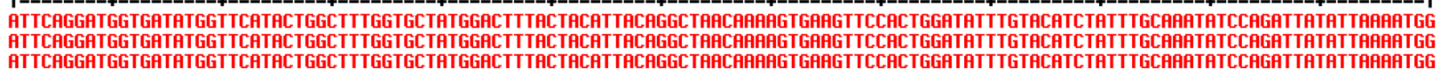 } \\
\hline & 651 & 660 & 670 & 680 & 690 & 700 & 710 & 720 & 730 & 740 & 750 & 760 & 770 & 780 \\
\hline $\begin{array}{r}\text { HPV-16 } \\
\text { seq } \\
\text { Consensus }\end{array}$ & $\begin{array}{l}\text { TGTO } \\
\text { TGTO } \\
\text { TGTC }\end{array}$ & & $\begin{array}{l}\text { GACAG } \\
\text { GACAG } \\
\text { GACAG }\end{array}$ & TTITT & FCCGAB & $\begin{array}{l}\text { ACFAAT } \\
\text { ACFART } \\
\text { ACARATC }\end{array}$ & GTTAGA & TATTTAF & $\begin{array}{l}\text { GCTGG } \\
\text { GCTGG } \\
\text { GCTGG }\end{array}$ & $\begin{array}{l}\text { IGTTGGT } \\
\text { IGTTGGT } \\
\text { IGTTGGT }\end{array}$ & $\begin{array}{l}\text { ATGTAC } \\
\text { ATGTAC }\end{array}$ & $\begin{array}{l}\text { CGATTT } \\
\text { CGATTT } \\
\text { ACGATTT }\end{array}$ & $\begin{array}{l}\text { ATTAF } \\
\text { ATTAP }\end{array}$ & $\begin{array}{l}\text { ICTGG } \\
\text { ICTGG } \\
\text { ICTGG }\end{array}$ \\
\hline
\end{tabular}

Figure 2. HPV-16 Multiple Sequence Alignment

\section{Discussion}

The HPV infection lead to the development of genital system cancers specially in the lower female genital tract (19), but the role of it in the upper genital tract cancers including OCa has not been fully elucidated (20). The etiology of OCa is multifactorial; the main causes are genetic, environmental, and sexual behavior and HPV which is the main pathogen that leads to OCa (21). Previous studies report different ranges of HPV prevalence in OCa, even some studies were unable to detect HPV in OCa (21-24). A wide range of study results do not demonstrate the exact prevalence of HPV and this could be because of different study conditions like the type of histopathology sampling, sample transferring and storage condition, the type of method that is used for HPV detection, molecular technique condi- tions, the time of the study, OCa stage, and patient conditions like age, race and ethnicity, sexual behavior, and the genetics. Therefore, the role of HPV in OCa tumor genesis is less clear due to the mentioned reasons. Most European studies have reported negative HPV detection results in OCa patients with a prevalence rang of $0 \%$ to $8 \% \mathrm{HPV}$ positive (22-26). In this study we detected $36 \%$ HPV-16 in the patients with OCa. In a study conducted by Roteh et al. in Iran (2012), seven of 44 (15.90\%) ovarian carcinoma and five of 50 (10\%) normal ovarian tissue were found positive for the common marker of HPV (27). Another study which was conducted by Alavi et al. in Iran (2012) represented that high-risk oncogenic HPV (HPV -18 and HPV -16) could not support any association with OCa, they reported that 3 of 50 OCa and 1 of 30 normal group as controls were 
HPV positive (28). So, previous studies have documented the increase of HPV-16 associated OCa in Iran. Atalay (2007) in Turkey reported 8.5 \% HPV in OCa patients (21). Rosa et al. (2013) in a meta-analysis study showed a range of $0 \%$ to $66.7 \%$ HPV prevalence with a mean of $17.5 \%$ in OCa patients and, more, reported the highest HPV prevalence in Asia at 31.4\%. In addition, they showed that the prevalence of HPV-16 increased during 2000 to 2005 and started to decrease after 2006 in OCa patients (24). The highest prevalence of HPV in OCa patients was $26.9 \%-35.9 \%$, all of whom were from China $(24,29,30)$. Our results, in comparison with previous studies, showed that the prevalence of HPV-16 in OCa patients has increased in our country; it, of course, could be predicted as the highest prevalence of $\mathrm{HPV}$ is in Asia among the continents. Several limitations of the present study should be discussed; the main obstacles for the current study are the small sample size and limited samples from specific geographic areas of Iran, which lead to heterogeneity and did not reflect a true statistical distribution. Another limitation is not detecting other types of HPV. Because of the high prevalence of HPV in Iran, we need future direction for predicting and detecting the people with high risks for OCa that are infected with human papilloma by subtyping HPV that must be recommended in infected people. Further studies are needed to understand the mechanisms of HPV-16 that lead to OCa whose pathogen is unclear until now. This study reports the high prevalence of HPV-16 in OCa in Iranian patients in spite of the fact that the relationship of HPV and OCa and the role of papilloma virus in tumor genesis of OCa remain inconclusive and further studies are needed to respond to that question.

\subsection{Conclusions}

Our results demonstrated the increase of HPV-16 associated ovarian cancer in our patients. There has been an indication of insufficient effort, like producing each new vaccine formulation, to prevent HPV-16 associated cancers. Various results and few publications in Iran have shown that further investigation is essential to instituting prevention programs.

\section{Acknowledgments}

This work was financially supported by Infertility and Reproductive Health Research Centre, Shahid Beheshti University of Medical Sciences, Tehran, Iran.

\section{Footnote}

Conflict of Interest: We declare that we have no conflict of interest.

\section{References}

1. Vinodhini K, Shanmughapriya S, Das BC, Natarajaseenivasan K. Prevalence and risk factors of HPV infection among women from various provinces of the world. Arch Gynecol Obstet. 2012;285(3):771-7. doi 10.1007/s00404-011-2155-8. [PubMed: 22159694].

2. Bosch FX, Lorincz A, Munoz N, Meijer CJ, Shah KV. The causal relation between human papillomavirus and cervical cancer.JClin Pathol. 2002;55(4):244-65. [PubMed: 11919208].

3. Liu X, Zhang S, Ruan Q, Ji Y, Ma L, Zhang Y. Prevalence and type distribution of human papillomavirus in women with cervical lesions in Liaoning Province, China. Int J Gynecol Cancer. 2010;20(1):147-53. doi: 10.1111/IGC.ob013e3181c20860. [PubMed: 20130516].

4. Steben M, Duarte-Franco E. Human papillomavirus infection: epidemiology and pathophysiology. Gynecol Oncol. 2007;107(2 Suppl 1):S2-5. doi: 10.1016/j.ygyno.2007.07.067. [PubMed: 17938014].

5. Robison K, Hosmer J, Murray A, Ruhul QM, Raker C. Prevalence of hpv and type distribution in southeast asian women residing in rhode Island. Austin J Obstet Gynecol. 2014;1(6):5.

6. de Sanjose S, Diaz M, Castellsague X, Clifford G, Bruni L, Munoz $\mathrm{N}$, et al. Worldwide prevalence and genotype distribution of cervical human papillomavirus DNA in women with normal cytology: a meta-analysis. Lancet Infect Dis. 2007;7(7):453-9. doi: 10.1016/S14733099(07)70158-5. [PubMed: 17597569].

7. Ishizaki A, Matsushita K, Hoang HT, Agdamag DM, Nguyen $\mathrm{CH}$, Tran VT, et al. E6 and E7 variants of human papillomavirus-16 and -52 in Japan, the Philippines, and Vietnam. J Med Virol. 2013;85(6):1069-76. doi: 10.1002/jmv.23566. [PubMed: 23588734].

8. Chen W, Zhang X, Molijn A, Jenkins D, Shi JF, Quint W, et al. Human papillomavirus type-distribution in cervical cancer in China: the importance of HPV 16 and 18. Cancer Causes Control. 2009;20(9):1705-13. doi: 10.1007/s10552-009-9422-z. [PubMed: 19705288].

9. Munoz N, Bosch FX, de Sanjose S, Vergara A, del Moral A, Munoz MT, et al. Risk factors for cervical intraepithelial neoplasia grade III/carcinoma in situ in Spain and Colombia. Cancer Epidemiol Biomarkers Prev. 1993;2(5):423-31. [PubMed: 8220086].

10. Munoz N, Bosch FX, de Sanjose S, Herrero R, Castellsague X, Shah KV, et al. Epidemiologic classification of human papillomavirus types associated with cervical cancer. $N$ Engl J Med. 2003;348(6):518-27. doi: 10.1056/NEJMoa021641. [PubMed: 12571259].

11. Paul MP, Iannuzzi MC. Sarcoidosis and immunologic lung. 2011

12. Schiffman M, Rodriguez AC, Chen Z, Wacholder S, Herrero R, Hildesheim A, et al. A population-based prospective study of carcinogenic human papillomavirus variant lineages, viral persistence, and cervical neoplasia. Cancer Res. 2010;70(8):3159-69. doi: 10.1158/00085472.CAN-09-4179. [PubMed: 20354192].

13. Dadashi M, Eslami G, Ghalavand Z, Goudarzi H, Fallah F, Owlia P . Prevalence of chlamydia trachomatis and mycoplasma genitalium in patients with benign and malignant ovarian cancer by nested pcr method. Novel Biomed. 2016;4(1):18-23.

14. Thanapprapasr D, Wilailak S. Screening for ovarian cancer in women, ovarian cancer-clinical and therapeutic perspectives. ; 2012.

15. Radojicic J, Zaravinos A, Spandidos DA. HPV, KRAS mutations, alcohol consumption and tobacco smoking effects on esophageal squamouscell carcinoma carcinogenesis. Int J Biol Markers. 2012;27(1):1-12. doi: 10.5301/JBM.2011.8737. [PubMed: 22020370].

16. Parkin DM, Monteleone P, Maj M, Fusco M, Orazzo C, Kemali D. The global health burden of infection-associated cancers in the year 2002. J Prev Med Public Health. 2001;34(4):372-8. 
17. Nakashima K, Shigehara K, Kawaguchi S, Wakatsuki A, Kobori Y, Nakashima K, et al. Prevalence of human papillomavirus infection in the oropharynx and urine among sexually active men: a comparative study of infection by papillomavirus and other organisms, including Neisseria gonorrhoeae, Chlamydia trachomatis, Mycoplasma spp., and Ureaplasma spp. BMC Infect Dis. 2014;14:43. doi: 10.1186/1471-233414-43. [PubMed: 24468054].

18. Lee JY, Kim SM, Park SJ, Lee SO, Choi SH, Kim YS, et al. A rapid and non-invasive 2-step algorithm for diagnosing tuberculous peritonitis using a $\mathrm{T}$ cell-based assay on peripheral blood and peritoneal fluid mononuclear cells together with peritoneal fluid adenosine deaminase. J Infect. 2015;70(4):356-66. doi: 10.1016/j.jinf.2014.09.012. [PubMed: 25305499].

19. Bilyk OO, Pande NT, Pejovic T, Buchinska LG. The frequency of human papilloma virus types 16,18 in upper genital tract of women at high risk of developing ovarian cancer. Exp Oncol. 2014;36(2):121-4. [PubMed: 24980768].

20. Macfarlane TV, Macfarlane GJ, Thakker NS, Benhamou S, Bouchardy C, Ahrens W, et al. Role of medical history and medication use in the aetiology of upper aerodigestive tract cancers in Europe: the ARCAGE study. Ann Oncol. 2012;23(4):1053-60. doi: 10.1093/annonc/mdr335. [PubMed: 21828376].

21. Atalay F, Taskiran C, Taner MZ, Pak I, Or M, Tuncer S. Detection of human papillomavirus DNA and genotyping in patients with epithelial ovarian carcinoma. J Obstet Gynaecol Res. 2007;33(6):823-8. doi: 10.1111/j.1447-0756.2007.00663.x. [PubMed: 18001449].

22. Anttila M, Syrjanen S, Ji H, Saarikoski S, Syrjanen K. Failure to demonstrate human papillomavirus DNA in epithelial ovarian cancer by general primer PCR. Gynecol Oncol. 1999;72(3):337-41. doi: 10.1006/gyno.1998.5264. [PubMed: 10053104].

23. Idahl A, Lundin E, Elgh F, Jurstrand M, Moller JK, Marklund I. Chlamy- dia trachomatis, Mycoplasma genitalium, Neisseria gonorrhoeae, human papillomavirus, and polyomavirus are not detectable in human tissue with epithelial ovarian cancer, borderline tumor, or benign conditions. Am J Obstet Gynecol. 2010;202(1):71.

24. Rosa MI, Silva GD, de Azedo Simoes PW, Souza MV, Panatto AP, Simon $\mathrm{CS}$, et al. The prevalence of human papillomavirus in ovarian cancer: a systematic review. Int J Gynecol Cancer. 2013;23(3):437-41. doi: 10.1097/IGC.0b013e318280f3e0. [PubMed: 23354370].

25. de Villiers EM, Schneider A, Gross G, zur Hausen H. Analysis of benign and malignant urogenital tumors for human papillomavirus infection by labelling cellular DNA. Med Microbiol Immunol. 1986;174(6):281-6. [PubMed: 3005812].

26. Runnebaum IB, Maier S, Tong XW, Rosenthal HE, Mobus VJ, Kieback DG, et al. Human papillomavirus integration is not associated with advanced epithelial ovarian cancer in German patients. Cancer Epidemiol Biomarkers Prev. 1995;4(5):573-5. [PubMed: 7549817].

27. Roteh SMSA, Fard ZT, Abdirad A, Moeini Z. Analysis of ovarian epithelial tumors for presence of human papillomavirus.J Mazandaran Univ Med Sci. 2012;22(87):22-27.

28. Alavi G, Sharifi N, Sadeghian A, Rezaei A, Shidaee H. Failure to demonstrate the role of high risk human papilloma virus in epithelial ovarian cancer. Iran J Pathol. 2012;7(3):151-6.

29. Ip SM, Wong LC, Xu CM, Cheung AN, Tsang PC, Ngan HY. Detection of human papillomavirus DNA in malignant lesions from Chinese women with carcinomas of the upper genital tract. Gynecol Oncol. 2002;87(1):104-11. [PubMed:12468350].

30. Li T, Lu ZM, Guo M, Wu QJ, Chen KN, Xing HP, et al. p53 codon 72 polymorphism $(\mathrm{C} / \mathrm{G})$ and the risk of human papillomavirusassociated carcinomas in China. Cancer. 2002;95(12):2571-6. doi: 10.1002/cncr.11008. [PubMed: 12467072]. 